\title{
Evaluation of Biological Soil Fertility Management Practices for Corn Production in Oxisols
}

\author{
Mupala G. Muyayabantu ${ }^{1}$, Bakach D. Kadiata ${ }^{1}$, Kabwe K. Nkongolo ${ }^{2 *}$ \\ ${ }^{1}$ Faculty of Agronomy, University of Kinshasa, Kinshasa, DR-Congo; ${ }^{2}$ Department of Biological Sciences, Laurentian University, \\ Sudbury, Canada. \\ Email: *knkongolo@laurentian.ca
}

Received August $5^{\text {th }}, 2012$; revised September 12 ${ }^{\text {th }}, 2012$; accepted October $15^{\text {th }}, 2012$

\begin{abstract}
Field trials on the management of soil biological fertility with aim to increasing corn production were conducted in a savannah region of the DR-Congo. Three organic matters including fresh biomass of Entada abyssinica, Tithonia diversifolia, Stylosanthes gracilis and a mineral combination of nitrogen and phosphorus (NP) (115-63-0) along with a control (without fertilization) were evaluated for corn crop growth and production. The field trial was a completely randomized design with four replicates. Plant height, basal stem diameter, and yield components were assessed. Irrespective of fertilization treatments and variety, maize showed a similar growth up to 20 days after sowing (DAS), and then two distinct trends were observed. At 60 DAS, plant height and basal diameter were significantly bigger in plots treated with NP, T. diversifolia and E. abyssinica compared to S. gracilis treatment and control (NoF). This pattern was also confirmed with agronomic traits such as cob length, number of kernel per cob, and net grain yield. The local variety was the least productive under any treatment. In general, the response of corn crop to organic and inorganic fertilization showed that the mineral combination (NP) increased the most grain yield and other yield components compared to unfertilized trial, followed by T. divessifolia and E. abyssinica. NP and T. diversifolia treatments increased significantly and equally soil potassium content compared to control and other treatments. Application of $T$. diversifolia appears a more cost effective approach for small farmers to improving fertility of the oxisol prevailing in Central Africa compared to mineral fertilizers.
\end{abstract}

Keywords: Oxisols; Organic and Inorganic Fertilization; Corn Crop Production; Soil Fertility; DR-Congo

\section{Introduction}

Maize is the third world most grown grain cereal after wheat and rice and is the main staple food in many subSaharan African countries including the DR-Congo. Its production in these region depends on the rain-fed traditional agriculture prone to slash-and-burn characterized by quick soil degradations. This agronomic system makes the soil very impoverished in nutrients.

In fact, soil factors are among the most determining constraints which affect the crop production in the developing countries, particularly under the tropics, where low levels of nitrogen and phosphorus especially constitute the most limiting factors to plant growth [1,2]. It is therefore necessary to replenish soil with these nutrients in order to sustain its productivity [3-5].

However, inorganic fertilizers which are known to increase the productivity of soil are rather difficult to access for farmers due to their high cost $[6,7]$. They also induce degradation of the ecosystems and cause some

"Corresponding author. risks for human health. In addition, farmers have limited knowledge on chemical fertilization application and management. Thus, organic farming stands to be the appropriate solution for improving and preserving soil fertility [8-10]. Use of organic manure remains one of the reliable ways to improving sustainably tropical acid soils in which high deficiency of available phosphorus prevails $[11,12]$. The main challenges are the determination of the required quantity of organic fertilizers, the assessment of a balanced ratio of nutrients from organic manures as well as the synchronization of their availability in response to crop demand $[7,13]$.

Kretzschmar et al. [14] reported that mulch application to sandy soil significantly induced a change in soil chemical characteristics such as $\mathrm{CEE}, \mathrm{pH}$, available $\mathrm{K}$ and $\mathrm{P}$ from $\mathrm{P}$ solubilization out of $\mathrm{Al}$ and $\mathrm{Fe}$ chelates in exchange of organic acids. The application of organic manure to soil is proven to improve chemical, physical and biological soil characteristics which increase nutrients availability and their assimilation by the crops [15]. Several studies have shown that use of $T$. diversifolia 
foliages increased crop yields through solubilization of available phosphorus $[7,16]$. It is thus assumed that the use of leafy biomass of S. gracilis, E. abyssinica or $T$. diversifolia could sustain fertility of nutrient-deficient oxisols.

Thus, the present study was undertaken with the objective of assessing three organic matters (E. abyssinica, T. diversifolia and S. gracilis) as manures compared to mineral N-P combination on corn crop production in a savannah region of DR-Congo.

\section{Materials and Methods}

\subsection{Study Site}

The study was carried out at the research station of the DR-Congo National Institute for Agronomic research (INERA) in Gandajika, in Eastern Kasaï province. The region falls within the Aw4 climate type according to Köppen classification characterized with 4 months of dry season (from mid-may to august) coupled with 8 months of rainy season, sometimes interrupted by a short dry season in January/February. Daily temperature averages $25^{\circ} \mathrm{C}$ and annual rainfall is close to $1500 \mathrm{~mm}$.

\subsection{Soil Characterization}

The study site was on one-year fallow and colonized mainly by Imperata cylindrica prior to the experiment setup. In general, the soil of the targeted locations of Eastern Kasaï (Gandajika) is made up of a sandy overlay on loamier sediment that often rests at low depth on an ancient lateritic slab. The adsorbing complex is relatively well saturated and it remains still some alterable minerals. The clay fraction less important seems not only constituted of kaolinite alongside in relation to the depth of loamy sediment. The site topsoil has a high rate of gravels and very few fine elements.

Soil samples were collected according to standard protocols. Soil $\mathrm{pH}$ was measured in water and a neutral salt solution $\mathrm{pH}\left(\mathrm{CaCl}_{2}\right)$. Total nutrients in soil samples were analyzed at MIRARCO laboratories in Sudbury (Ontario, Canada) following the procedure outlined by Abedin et al. (2012). Aqua Regia extraction was used. A 0.5 to $0.05 \mathrm{~g}$ soil sample was digested with $5 \mathrm{ml}$ each of concentrated $\mathrm{HNO}_{3}$ and HCL using a MARS 5 Microwave Oven, with the supernatant made to $50 \mathrm{ml}$ volume with deionized water for analysis by a combination of Inductively-Coupled Plasma-Optical Emission Spectrometry (ICP-AES), inductively-coupled Pasma-Mass Spectrometry (ICP-MS) and hydride generation atomic emission spectrometry (HG-AAS). The quality control measures included duplicate samples, internal blind reference materials (IRM'S), spiked blanks, spiked replicates, reagents/instrument blanks, preparation control samples, certified reference materials and instrument control samples. Detection procedures for carbon and nitrogen were as described by Abedin et al. [17].

Bioavailable potassium and phosphorus were estimated by extracting $5 \mathrm{~g}$ of soil with $20 \mathrm{ml}$ of $0.01 \mathrm{M}$ $\mathrm{LiNO}_{3}$ in a 50-ml centrifuge tubes in a shaker under ambient lighting conditions for 24 hours at $20^{\circ} \mathrm{C}$ [17]. The pHs $\left(\mathrm{LiNO}_{3}\right)$ of the suspension was measured prior to centrifugation at $3000 \mathrm{rpm}$ for 20 minutes, with filtration of the supernatant through a 0.45 um filter into a $20 \mathrm{ml}$ polyethylene tube and made to volume with deionized water. The filtrate was preserved at approximately $3^{\circ} \mathrm{C}$ for chemical analysis by ICP-MS. The quality control program completed in an ISO 17025 accredited facility (Elliot Lake Research Field Station of Laurentian University) included analysis of duplicates, Internal Reference Materials (IRM's), procedural and calibration blanks, with continuous calibration verification and use of internal standards to correct for any mass bias. All concentrations were calculated in mass/mass dry soil basis.

The data for the nutrient levels in soil samples were analyzed using SPSS 7.5 for Windows, with all data being transformed using a $\log _{10}$ transformation to achieve a normal distribution. Variance-ratio test was done with an assumption of data normality in the underlying population distributions of the data. ANOVA, followed by Tukey's HSD multiple comparison analysis, were performed to determine significant differences $(p=0.05)$ among the sites. Data from analysis of samples from limed and no limed areas were compared using Student $-\mathrm{T}$ test.

\subsection{Genetic Material}

The plant materials include three corn (Zea mays L.) varieties, one local (Varloc) and two genetically improved accessions (Mus and Salongo II). All varieties were provided by the INERA research station in Gandajika. Leafy biomass of $T$. diversifolia and E. abyssinica were collected from trees in the surroundings of Gandajika while S. gracilis leaves were collected from old pastures.

\subsection{Experimental Trials}

The land was tractor-plowed, harrowed and surface-leveled with hoes before delimitating experimental plots within blocks. Field trials were undertaken using a randomized complete block design with four replicates. The treatments include a control (NoF), a mineral fertilizer consisting of a combination of nitrogen and phosphorus (NP 115-63), organic manures with E. abyssinica (E), T. diversifolia (T) and S. gracilis (S). The quantity of organic matters to be applied was determined according to Ikerra et al. (2007) at a rate of $10 \mathrm{~kg}$ of leafy biomass per plot representing $8 \mathrm{t} \cdot \mathrm{ha}^{-1}$. Each block measured $21 \mathrm{~m} \times$ 
$20.5 \mathrm{~m}$ and was made of 20 plots of $4 \mathrm{~m} \times 3 \mathrm{~m}$ separated by $1.5 \mathrm{~m}$ and $2 \mathrm{~m}$ within and between blocks, respectively.

The organic fertilizers were applied four days prior to sowing through soil incorporation alongside the sowing rows while the di-ammonium phosphate (DAP) was locally applied around seedlings ten days after sowing (DAS) and, then supplemented with urea 30 days later. Corn seeds were sown in holes at $1 \mathrm{~m} \times 1 \mathrm{~m}$ spacing, at \pm $4 \mathrm{~cm}$ depth.

To assess the effect of each treatment on the three varieties under trial, plant growth (height and stem base diameter) at 10, 20, 30, 40, 50 and 60 DAS and yield components (cob length, numbers of grain rows and of grains by cob, net yield) were determined. The growth measurements were performed in morning up to 60 DAS while yield parameters were assessed at crop harvest. Corn cobs length was measured and then kernel rows counted. Grains were sun-dried up to $17 \%$ of moisture content and later counted and then weighed to determine the net yield.

To compare the effect of various treatments on corn crop, collected data were subjected to the analysis of variance (ANOVA) using the GENSTAT software (Ed. Discovery Free Version). The least significant difference (LSD) test and Tukey's HSD multiple comparison analysis served in separating treatment means at $5 \%$ probability level.

\section{Results}

\subsection{Soil Nutrient Content}

Previous analyses of the soil at experimental sites revealed no significant differences for nutrient content and distribution as well as the $\mathrm{pH}$ levels. In the present study, nutrient content in soil at plant maturity stage was assessed after various treatments. There were significant differences for total potassium in plots fertilized with NP, E. abyssinica, and T. diversifolia compared to soils from control sites (Tables $\mathbf{1}$ and 2). The highest amount of this nutrient was found in soil from NP and T. diversifolia treatments. No significant differences were observed among soil samples for total phosphorus content. The total level of nitrogen was below detectable levels in all the samples analyzed. The proportion of total nutrient that was phytoavailable (bioavailable) was determined for each element with the analytical results revealing that most of the total nutrient in the soil matrix is not in forms available for plant uptake. For example, the amount of bioavailable potassium varied from $9.95 \mathrm{mg} \cdot \mathrm{kg}^{-1}$ to 14.0 $\mathrm{mg} \cdot \mathrm{kg}^{-1}$ and from no detectable to $0.54 \mathrm{mg} \cdot \mathrm{kg}^{-1}$ for phosphorus (Table 1). Soil $\mathrm{pH}$ was not affected by any treatment with values varying from 5.08 to 5.18 (Table 2). Soil samples from plots treated with $S$. gracilis were
Table 1. Total and bioavailable (in parenthesis) concentrations of nutrients in soil samples from areas treated with inorganic [Nitrogen-Phosphorus (NP)], and organic matters [Entada abyssinica (E) and Tithonia diversifolia (T)] in Gandajika-DR-Congo.

\begin{tabular}{cccc}
\hline \multirow{2}{*}{ Treatments } & \multicolumn{3}{c}{ Elements $\left(\mathrm{mg} \cdot \mathrm{kg}^{-1}\right)$} \\
\cline { 2 - 4 } & $\mathrm{N}$ & $\mathrm{P}$ & $\mathrm{K}$ \\
\hline NoF & $<\mathrm{DL}$ & $121(0.54)$ & $95(10.2)$ \\
$\mathrm{NP}$ & $<\mathrm{DL}$ & $119(<\mathrm{DL})$ & $402(9.25)$ \\
E. abyssinica & $<\mathrm{DL}$ & $112(<\mathrm{DL})$ & $238(9.95)$ \\
T. diversifolia & $<\mathrm{DL}$ & $108(0.53)$ & $371(14.0)$ \\
LSD $(\mathrm{p}=0.05)$ & - & 19.5 & $58(5.1)$ \\
\hline
\end{tabular}

Data in parenthesis represents concentrations for bioavailable nutrients. $<\mathrm{DL}$ means that the data are below the detectable level of $0.084 \%$ for Nitrogen and $0.369 \mathrm{mg} \cdot \mathrm{kg}^{-1}$ for phosphorus.

Table 2. pH and carbon concentrations in in soil samples from areas treated with inorganic [Nitrogen-Phosphorus (NP)], and organic matters [Entada abyssinica (E) and Tithonia diversifolia (T)] in Gandajika-DR-Congo.

\begin{tabular}{cccc}
\hline Treatments & Carbon (\%) & $\mathrm{pH}\left(\mathrm{H}_{2} \mathrm{O}\right)$ & $\mathrm{pH}\left(\mathrm{CaCl}_{2}\right)$ \\
\hline NoF-1 & 0.632 & 5.15 & 4.46 \\
NP-1 & 0.565 & 5.18 & 4.46 \\
E. abyssinica & 0.577 & 5.08 & 4.37 \\
T. diversifolia & 0.526 & 5.17 & 4.53 \\
LSD (p=0.05) & 0.08 & 0.35 & 0.29 \\
\hline
\end{tabular}

not included in this nutrient analysis.

\subsection{Plant Growth}

Plant heights for corn varieties under different fertilizers treatments are illustrated in Figure 1. Irrespective of varieties, two trends of plant growth were discernable from 20 DAS. The first pattern showed a rapid growth rate of all genotypes fertilized with the NP mineral combination, T. diversifolia (T) as well as E. abyssinica (E) compared to control. The second trend was a slow growth rate based on height measurements for the plants growing in plots fertilized with S. gracilis and in unfertilized plots. Throughout the growth period, all corn varieties remained below $60 \mathrm{~cm}$ of height for these later treatments (Figure 1).

Basal stem diameter growth for all varieties exhibited the same trend from 10 to $60 \mathrm{DAS}$ with the NP mineral combination, T. diversifolia (T) as well as E. abyssinica (E) showing significant effects compared to control (Figure 2). These growths varied with corn varieties evaluated. From 10 to 20 DAS, the control (NoF), the NP combination as well as $S$. gracilis supply could not significantly stimulate the basal stem diameter growth of 

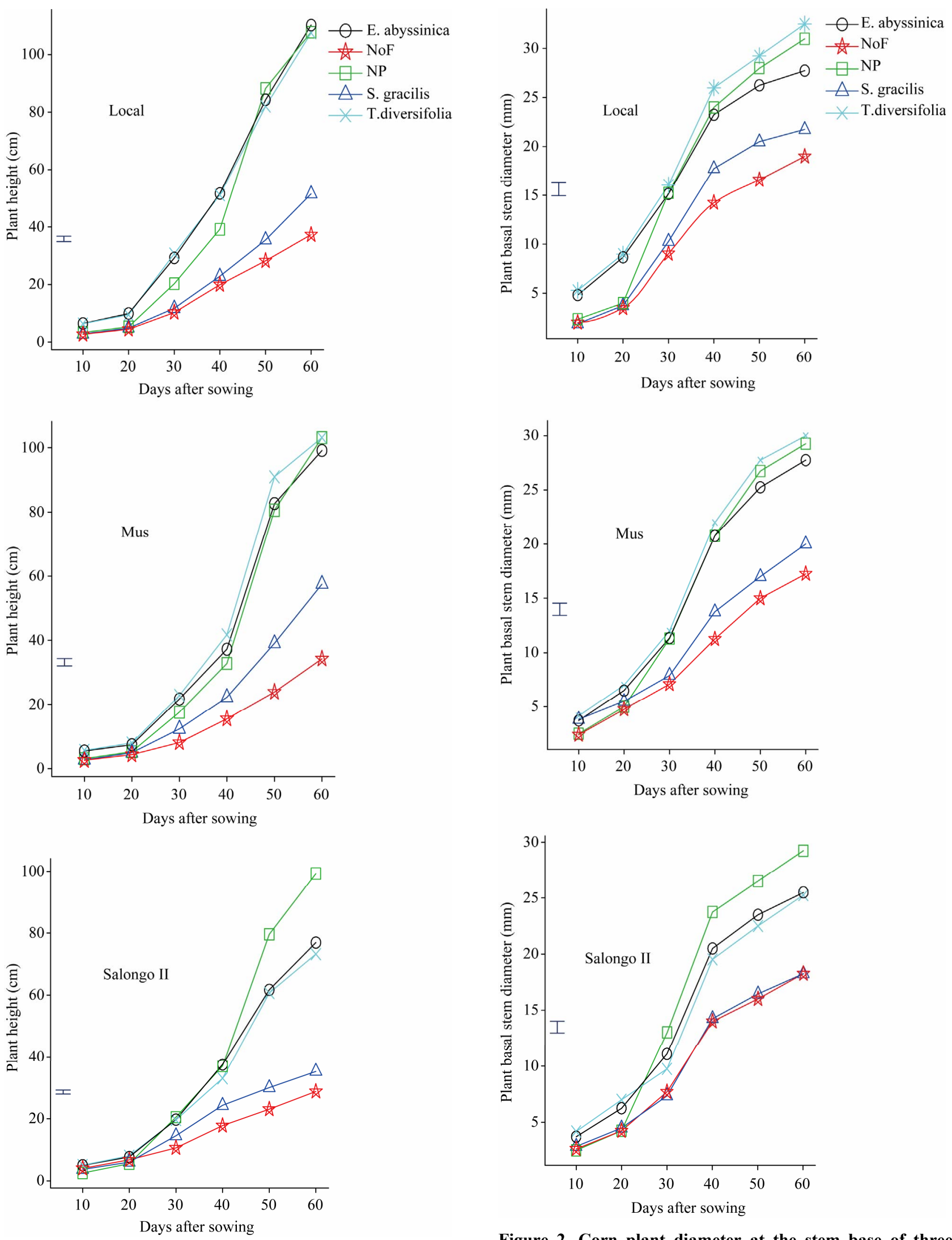

Figure 1. Plant height of three corn varieties as under different fertilization regimes in Gandajika (DR-Congo).

Figure 2. Corn plant diameter at the stem base of three corn varieties subjected to different fertilization regimes in Gandajika (DR-Congo). 
Varloc (Figure 2). From 10 DAS, Varloc under E. abyssinica and $T$. diversifolia applications showed a stem base diameter growth significantly $(p=0.05)$ greater than under other treatments. The average diameter measures after 20 DAS were similar for all the three varieties for plots under NP combination, E. abyssinica and T. diversifolia treatments. Plants in control trial $(\mathrm{NoF})$ and $S$. gracilis treatment (Figure 2) showed the smallest diameter growth, although each variety performed variably.

\subsection{Crop Yield}

The mean numbers of corn cobs were significantly $(p=$ 0.05 ) higher under NP combination, T. diversifolia and $E$. abyssinica compared to control (NoF) and S. gracilis treatments (Table 3). Analysis of kernel rows per cob also showed that the unfertilized treatment and the application of S. gracilis resulted in the lowest numbers of rows irrespective of varieties (Table 3). The highest numbers of rows ranged from 13 to 16 for other treatments. Likewise, the numbers of grains per cob was significantly $(\mathrm{p}=0.05)$ higher under NP combination, $E$. abyssinica and $T$. diversifolia treatments with an average of 425 grains, compared to unfertilized control ( $\mathrm{NoF}$ ) and the $S$. gracilis treatment that yielded less than 300 kernels per cob irrespective of crop varieties (Table 4).

For grain production, Mus variety under NP treatment had the highest net yield $\left(3.134 \mathrm{t} \cdot \mathrm{ha}^{-1}\right)$, followed by $T$. diversifolia $\left(2.324 \mathrm{t} \cdot \mathrm{ha}^{-1}\right)$ and E. abyssinica $\left(2.271 \mathrm{t} \cdot \mathrm{ha}^{-1}\right)$, S. gracilis and the control (NoF), respectively (Figure 3). This trend was the same for the Salongo II and the local varieties.

\section{Discussion}

In general, nutrients and metal adsorption by plants is relatively low at low $\mathrm{pH}$ values. Adsorption then increases at intermediate $\mathrm{pH}$ from near zero to near complete adsorption over a relatively small $\mathrm{pH}$ range [18]. The more acid is the soil, the more zinc, manganese, copper, iron, and aluminum will be dissolved into the soil. In very acid soils with $\mathrm{pH}$ below 5.5 such as soil from the experimental sites of the present study, the availability of manganese and aluminum is increased to the point that they could become toxic to plants $[19,20]$. Calcium and magnesium deficiency along with reduced nitrogen transformations are also major problems associated with acid soils $[19,20]$. It should be pointed out that corn crop requires a $\mathrm{pH}$ ranging between 5.5 and 7 for optimal growth.

The initial slow plant growth during the first 20 DAS for all treatments could reflect the initial low level of soil fertility mostly for N [6]. However, it is likely that beyond this period, the mineralization of $T$. diversifolia and E. abyssinica biomass in soil was significant. This promoted a dynamic growth of corn plants compared to $S$. gracilis and the control treatments.

Moreover, the NP application did likely coincide with mineralization of $T$. diversifolia and E. abyssinica that released equivalent amount of nutrients to corn crop [14]. This could explain the similarity for plant growth among these treatments. In general, the assimilation of nutrients depends on genetics of each variety studied. That is reflected by the variable responses of the three varieties evaluated. This occurred in three phases for each of the varieties. The first phase was slow from 10 to 20 DAS, corresponding to the period of slow assimilation; the second was exponential and extended from 20 to 50 days, matching with the intense period of activity and of fast assimilation of nutrients by corn plants. The last phase from 50 to 60 DAS marked the end of the ascending growth cycle. On the other hand, the poor plant growth (height and diameter at stem base) observed with the $S$. gracilis treatment could be ascribed to the slow decomposition rate of this organic matter that is rich in cellulose and lignin. The decomposition of such a biomass requires more energy. In this case, a strong competition for nutrients (immobilization) probably occurred between soil microorganisms and corn plants and resulted in a

Table 3. Cob length and number of kernel rows of three maize varieties under different fertilization regimes with inorganic [Nitrogen-Phosphorus (NP)], and organic [Entada abyssinica (E), Tithonia diversifolia (T), and Stylosanthes gracilis] fertilizers in Gandajika-DR-Congo.

\begin{tabular}{ccccccc}
\hline \multirow{2}{*}{ Fertilizer } & \multicolumn{3}{c}{ Cob length $(\mathrm{cm})$} & \multicolumn{3}{c}{ Kernel rows per cob } \\
\cline { 2 - 7 } & Varloc & Mus & Salongo II & Varloc & Mus & Salongo II \\
\hline NoF & $7.8 \mathrm{c}$ & $5.1 \mathrm{c}$ & $6.0 \mathrm{~d}$ & $8.5 \mathrm{~b}$ & $6.0 \mathrm{~d}$ & $7.3 \mathrm{c}$ \\
$\mathrm{NP}$ & $12.5 \mathrm{a}$ & $15.5 \mathrm{a}$ & $14.5 \mathrm{a}$ & $13.8 \mathrm{a}$ & $16.0 \mathrm{a}$ & $15.0 \mathrm{a}$ \\
E. abyssinica & $11.8 \mathrm{~b}$ & $12.9 \mathrm{~b}$ & $12.3 \mathrm{~b}$ & $13.3 \mathrm{a}$ & $14.5 \mathrm{~b}$ & $14.5 \mathrm{~b}$ \\
T. diversifolia & $12.1 \mathrm{a}$ & $12.8 \mathrm{~b}$ & $14.4 \mathrm{a}$ & $13.5 \mathrm{a}$ & $14.3 \mathrm{~b}$ & $15.8 \mathrm{a}$ \\
S. gracilis & $8.6 \mathrm{c}$ & $7.8 \mathrm{c}$ & $7.1 \mathrm{c}$ & $9.5 \mathrm{~b}$ & $9 \mathrm{c}$ & $7.8 \mathrm{c}$ \\
\hline
\end{tabular}

Within a column, mean numbers followed by the same letter are not significantly different at $\mathrm{p}=0.05$ based on Tukey's HSD multiple comparison analysis. 


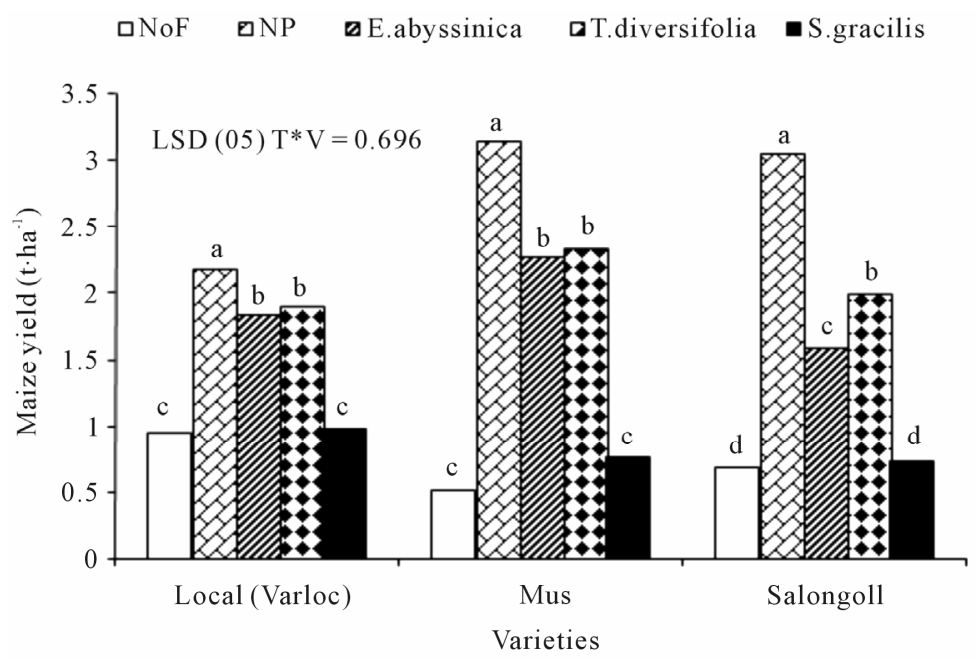

Figure 3. Net yield $\left(t \cdot h^{-1}\right)$ of three corn varieties under different fertilization regimes in Gandajika (DR-Congo).

Table 4. Numbers of maize kernels per cob of three maize varieties under different fertilization regimes with inorganic [Nitrogen-Phosphorus (NP)], and organic [Entada abyssinica (E), Tithonia diversifolia (T), and Stylosanthes gracilis] fertilizers in Gandajika-DR-Congo.

\begin{tabular}{cccc}
\hline \multirow{2}{*}{ Fertilizer } & \multicolumn{3}{c}{ Maize varieties } \\
\cline { 2 - 4 } & Varloc & Mus & Salongo II \\
\hline NoF & $204 \mathrm{c}$ & $158 \mathrm{~d}$ & $190 \mathrm{c}$ \\
NP & $404 \mathrm{a}$ & $540 \mathrm{a}$ & $483 \mathrm{a}$ \\
E. abyssinica & $346 \mathrm{~b}$ & $404 \mathrm{c}$ & $436 \mathrm{~b}$ \\
T. diversifolia & $330 \mathrm{~b}$ & $454 \mathrm{~b}$ & $438 \mathrm{~b}$ \\
S. gracilis & $209 \mathrm{c}$ & $238 \mathrm{~d}$ & $189 \mathrm{c}$ \\
\hline
\end{tabular}

Within a column, means followed by the same letter are not significantly different at $p=0.05$ level based on Tukey's HSD multiple comparison analysis.

poor height growth. Few S. gracilis leaves that decomposed earlier might have contributed to the rapid growth of corn crop resulting to the high plant height observed in plots treated with this organic matter compared to the control. The cob length and kernel rows per cob (R/C) seem to follow the same pattern as does the crop yield. The low level of nutrients especially nitrogen in soil at plant maturity suggested that most of the available elements were up taken by plants resulting in slight or no changes of this oxisol chemistry.

The level of soil fertility and $\mathrm{pH}$ is strongly correlated with corn yield which depends on the inherent genotypes of crop varieties under study. Ikerra et al. [7] reported that application of Tithonia alone increased soil exchangeable $\mathrm{Ca}$ content and the solubility of $\mathrm{P}$ available while significantly reducing the exchangeable $\mathrm{Al}$ and increasing soil $\mathrm{pH}$ with a consequent significant increase of maize yield equivalent to the application of Tithonia associated to TSP. The same authors reported that T. diversifolia increased the $\mathrm{pH}$ of acid soil in Tanzania most probably due to a high $\mathrm{Ca}$ concentration. This could be also valid for E. abyssinica. Such results are consistent with Cong [21] and George et al. [22] data that showed a similar rise in $\mathrm{pH}$ due to the application of Tithonia in Vietnam and Kenya, respectively. But the results of the present study, revealed no significant changes in $\mathrm{pH}$ among soil treatments.

\section{Conclusion}

A similar growth pattern was observed for all varieties studied during the first 20 days after sowing regardless of fertilizing treatments applied. After this stage, two distinct growth trends arose that revealed the efficiency of NP, T. diversifolia and E. abyssinica treatments over $S$. gracilis and the control. This trend was also duly translated into net dry grain yield per ha. The local variety was the least productive under any treatment. Although the NP application increased significantly the net grain yield and other agronomic parameters over T. diversifolia, the differences observed between the effects of these two treatments do not justify the cost of mineral fertilizers. Thus, soil application of T. diversifolia and E. abyssinica manures could be recommended as a biological approach of managing the fertility of the oxisol prevailing in Central part of D. R. Congo. The adoption of such practice is likely to be high considering the low incomes of local farmers.

\section{Acknowledgements}

This research was conducted through a partnership between Laurentian University (Ontario, Canada), University of Kinshasa (DR-Congo), and Caritas Congo. The authors are grateful to the Canadian International Devel- 
opment agency (CIDA) for financial support.

\section{REFERENCES}

[1] B. T. Kang and G. G. Wilson, "The Development of Alley Cropping as a Promising Agroforestry Technology," In: H. A. Steppler and P. K. R. Naïr, Eds., Agroforestry: A Decade of Development, ICRAF, Nairobi, 1987, pp. 227243.

[2] B. D. Kadiata and K. Lumpungu, "Differential Phosphorus Uptake and Use Efficiency among Selected Nitrogen-Fixing Tree Legumes over Time," Journal Plant Nutrition, Vol. 26, No. 5, 2003, pp. 1009-1022. doi:10.1081/PLN-120020072

[3] E. M. A. Smaling, J. J. Stoorvogel and P. N. Windmeijier, "Calculating Soil Nutrient Balances in Africa at Different Scales. II District Scale," Fertilizer Research, Vol. 35, 1993, pp. 237-250. doi:10.1007/BF00750642

[4] E. M. A. Smaling, J. J. Stoorvogel and P. N. Windmeijier, "Classifying Monitoring and Improving Soil Nutrient Stocks and Flows in Africa Agriculture," Ambio, Vol. 25, No. 8, 1996, pp. 492-496.

[5] N. Sanginga, O. Lyasse, J. Diels and R. Merckx, "Balanced Nutrient Management Systems for Cropping Systems in the Tropics: From Concept to Practice," Agriculture, Ecosystems, and Environment, Vol. 100, No. 2-3, 2003, pp. 99-102. doi:10.1016/S0167-8809(03)00177-4

[6] S. K. A. Danso and D. L. Eskew, "How to Improve Biological Nitrogen Fixation," FAO/AIEA Bulletin, Vol. 26, No. 2, 1985, pp. 29-32.

[7] S. T. Ikerra, E. Semu and J. P. Mrema, "Combining Tithonia diversifolia and Minjingu Phosphate Rock for Improvement of P Availability and Maize Grain Yields on a Chromic acrisol in Morogoro, Tanzania," In: A. Bationo, B. Waswa, J. Kihara and J. Kimetu, Eds., Advances in Integrated Soil Fertility Management in Sub-Saharan Africa: Challenges and Opportunities, Springer, Amsterdam, 2007, pp. 333-344.

[8] C. A. Palm, R. J. K. Myers and S. M. Nandwa, "Combined Use of Organic and Inorganic Nutrients Sources for Soil Fertility Replenishment," In: R. Buresh, Ed., Replenishing Soil Fertility in Africa, SSSA, Special Publication No. 51, 1997, pp. 193-217.

[9] P. Mäder, A. Fliessbach, D. Dubois, L. Gunst, P. Frieed and U. Niggli, "Soil Fertility and Biodiversity in Organic Farming," Science, Vol. 29, 2002, pp. 19-197.

[10] Y. Dumas, M. Dadomo, G. Di Lucca and P. Glorier, "Effects of Environmental Factors and Agricultural Techniques on Antioxidant Content of Tomatoes," Journal of the science of Food and Agriculture, Vol. 83, No.5, 2003, pp. 369-382. doi:10.1002/jsfa.1370

[11] F. M. Kihanda, G. P. Werren and A. N. Micheni, "Effects of Manure Application on Crop Yield and Soil Chemical Properties in a Long-Term Field Trial in Semi-Arid Kenya," In: A. Bationo, B. Waswa, J. Kihara and J. Kimetu, Eds., Advances in Integrated Soil Fertility Management in Sub-Saharan Africa: Challenges and Opportunities, Springer, Amsterdam, 2007, pp. 471-485. doi:10.1007/978-1-4020-5760-1 44

[12] A. B. Kwabiah, N. C. Stoskopf, C. A. Palm, R. P. Voroney, M. R. Rao and E. Gacheru, "Phosphorus Availability and Maize Response to Organic and Inorganic Fertilizer Imput in a Short Term Study in Western Study in Western Kenya," Agricultures, Ecosystems, and Environment, Vol. 95, 2003, pp. 49-59.

[13] A. Heeb, B. Lundegårdh, G. Savage and T. Ericsson, "Impact of Organic and Inorganic Fertilizers on Yield, Taste, and Nutritional Quality of Tomatoes," Journal of Plant Nutrition and Soil Sciences, Vol. 169, No 4, 2006, pp. 535-541. doi:10.1002/jpln.200520553

[14] R. M. Kretzschmar, H. Hafner, A. Bationo and H. Marschner, "Long-and Short-Term Effects of Crop Residues on Aluminium Toxicity, Phosphorus Availability and Growth of Pearl Millet in an Acid Sandy Soil," Plant Soil, Vol. 136, 1991, pp. 215-223. doi:10.1007/BF02150052

[15] J. R. Okalebo, C. O. Othieno, P. L. Woomer, N. K., Karanja, J. R. M. Semoka, M. A., Bekunda, D. N. Mugendi, R. M. Muasya, A. Bationo and E. J. Mukhwana, "Available Technologies to Replenish Soil Fertility in East Africa," In: A. Bationo, B. Waswa, J. Kihara and J. Kimetu, Eds., Advances in Integrated Soil Fertility Management in Sub-Saharan Africa: Challenges and Opportunities, Springer, Amsterdam, 2007, pp. 45-62. doi:10.1007/978-1-4020-5760-1_3

[16] G. Nziguheba, R. Merckx, C. A. Palm and P. Mutuo, "Combining Tithonia diversifolia and Fertilizers for Maize Production in Phosphorus Deficient Soil in Kenya," Agroforestry System, Vol. 55, No. 3, 2002, pp. 165-174.

[17] J. Abedin, P. Beckett and G. Spiers, "An Evaluation of Extratants for Assessment of Metal Phytoavailability to Guide Practices in Acidic Soils in Northern Regions," Canadian Journal of Soil Sciences, Vol. 92, No. 1, 2012, pp. 253-268. doi:10.4141/cjss2010-061

[18] H. B. Bradl, "Adsorption of Heavy Metal Ions on Soils and Soils Constituents," Journal of Colloid Interface Sciences, Vol. 277, No. 1, 2004, pp. 1-18. doi:10.1016/j.jcis.2004.04.005

[19] K. Winterhalder, "Dynamics of Plant Communities and Soils in Revegetated Ecosystems: A Sudbury Case Study," In: J. Gunn, Ed., Restoration and Recovery of an Industrial Region: Progress in Restoring the SmelterDamaged Landscape near Sudbury, Canada, SpringerVerlag, New York, 1995, pp. 173-182.

[20] K. Winterhalder, "Environmental Degradation and Rehabilitation of the Landscape around Sudbury, a Major Mining and Smelting Area," Environmental Reviews, Vol. 4, No. 3, 1996, pp. 185-224. doi:10.1139/a96-011

[21] P. T. Cong, "Improving Phosphorus Availability in Selected Soils from the Uplands of South Vietnam by Residue Management. A Case Study: Tithonia diversifolia", Ph.D. Thesis No. 439, Katholieke Universiteit, Leuven, 2000.

[22] T. S. George, P. J. Gregory, J. S. Robinson, R. J. Buresh and B. Jama, "Utilization of Soil Organic Phosphorus by Agroforestry and Crop Species in Field in West Kenya," Plant Soil, Vol. 246, 2002, pp. 53-63. doi:10.1023/A:1021575532546 